In der Rubrik „Literatur kompakt" werden die wichtigsten Originalarbeiten aus der internationalen Fachliteratur referiert.

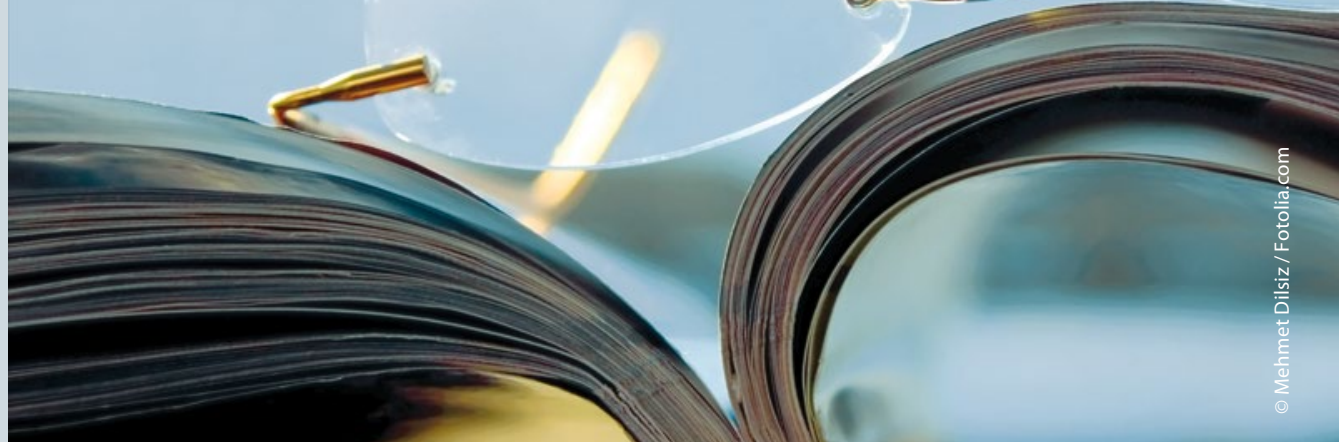

\section{Phytoöstrogene gegen Hitzewallungen und vaginale Trockenheit}

\begin{abstract}
Gegen Beschwerden in und nach der Menopause vertrauen viele Frauen auf pflanzliche Präparate. In einer Metaanalyse von mehr als 60 Studien haben niederländische Forscher die Wirkung der Phytotherapeutika überprüft.
\end{abstract}

$\mathrm{H}$ itzewallungen und Nachtschweiß sind Symptome, die menopausalen Frauen zu schaffen machen können. Der in Studien ermittelte Anteil Betroffener liegt zwischen $50 \%$ und $80 \%$. Auch eine

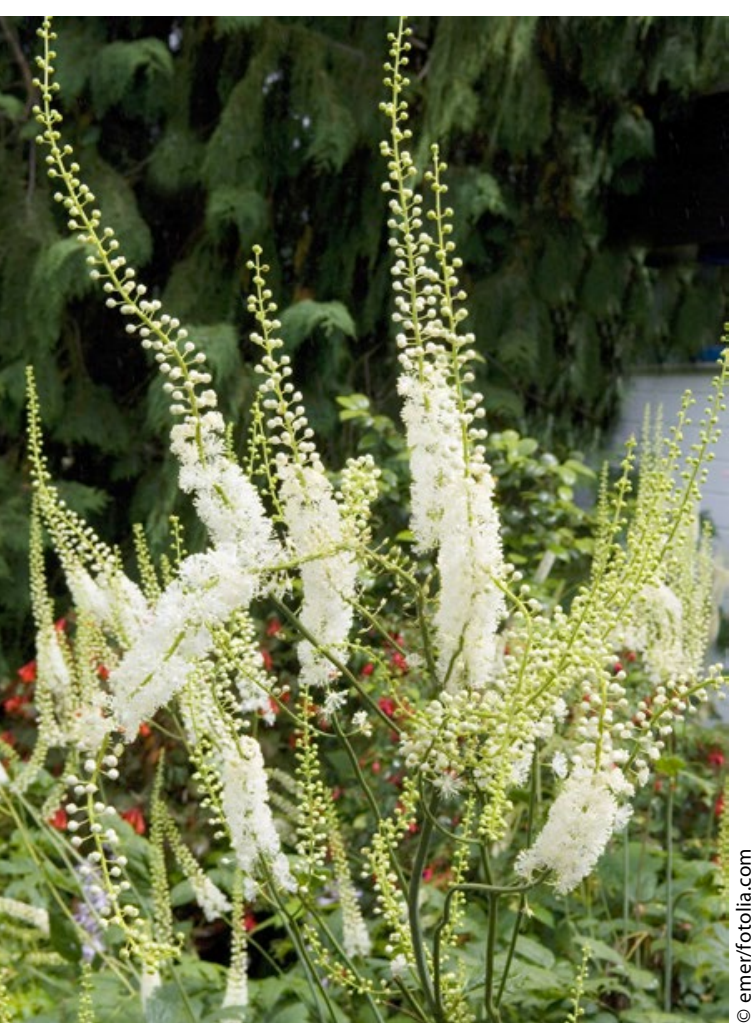

Phytotherapeutikum Traubensilberkerze trockene Scheide kann erhebliche Beschwerden verursachen. Gegen all diese Probleme würde eine Hormonersatztherapie helfen.

Viele Frauen - manchen Erhebungen zufolge bis zu $50 \%$ - möchten keine Hormone und setzen daher bei menopausalen Beschwerden auf die Komplementärmedizin. Im Vordergrund steht dabei die Einnahme von Phytoöstrogenen beispielsweise Isoflavonen aus Soja und Sojaextrakten. Auch Kräuter wie Wiesenklee und Traubensilberkerze gelten als wirksam. Und auch die chinesische Kräutermedizin gehört zum Sortiment.

Fundierte medizinisch-wissenschaftliche Wirknachweise sind zu den angebotenen Präparaten jedoch nicht immer verfügbar. Franco et al. haben im Zuge einer Metaanalyse 62 Studien zum Einsatz von pflanzlichen Produkten gegen menopausale Beschwerden gesichtet. Dabei verzeichneten die Forscher durchaus Effekte, wenn sich deren Ausmaß auch in Grenzen hielt.

Phytoöstrogene verminderten die Häufigkeit von Hitzewallungen gegenüber Placebo signifikant, und zwar im Durchschnitt um täglich 1,3 Attacken. Auch die vaginale Trockenheit verbesserte sich verglichen mit Placebo im Schnitt um 0,3 Punkte auf einer Skala von 0 bis 3 (höchster Schweregrad).
Keinen Einfluss hatten Phytoöstrogene auf das Symptom Nachtschweiß. Etwas inkonsistenter fielen die Ergebnisse für andere Phytoöstrogenquellen wie zum Beispiel Wiesenklee und Traubensilberkerze aus. In manchen Studien besserten sich die vasomotorischen Symptome durch diese Präparate, in anderen dagegen nicht. Rhapontik-Rhabarber war in einer Studie insofern erfolgreich, als er die Frequenz von Hitzewallungen senkte.

Grundsätzlich ging die Tendenz bei der Kräutermedizin in Richtung Linderung der vasomotorischen Beschwerden. Eine Ausnahme bildeten Heilkräuter aus der chinesischen Medizin. Die Studien hierzu ergaben Widersprüchliches, im Allgemeinen war kein Einfluss auf die postmenopausale Symptomatik festzustellen.

Die Einnahme gemischter und spezifischer Phytoöstrogene sei tatsächlich mit einer mäßig reduzierten Häufigkeit von Hitzewallungen und einer besseren Befeuchtung der Vagina verbunden, bilanzierten Franco und Mitarbeiter die Ergebnisse ihrer Analyse. Allerdings sei die Qualität der untersuchten Studien nicht optimal gewesen.

Speziell führten die Autoren an, dass Daten zu den möglichen Nebenwirkungen einer langfristigen Behandlung mit solchen Präparaten fehlten. Da die Phytoöstrogene ja östrogenartig wirkten, seien auch unerwünschte Effekte, beispielsweise eine endometriale Hyperplasie denkbar.

Dr. Robert Bublak

Franco $\mathrm{OH}$ et al. Use of Plant-Based Therapies and Menopausal Symptoms. JAMA 2016; 315: 2554-63 